\title{
A novel bio-sensor for registration of biting force in occlusally reactive single mandibular implant overdenture
}

\author{
Fahad H. Banasr, Manal R. Alammari \\ Oral and Maxillofacial Rehabilitation, Faculty of Dentistry, Dental Hospital, King Abdulaziz University, Jeddah, Saudi Arabia \\ Email: malammari@kau.edu.sa
}

Received 26 July 2013; revised 26 August 2013; accepted 20 September 2013

Copyright (C) 2013 Fahad H Banasr, Manal R Alammari. This is an open access article distributed under the Creative Commons Attribution License, which permits unrestricted use, distribution, and reproduction in any medium, provided the original work is properly cited.

\begin{abstract}
Mandibular single denture opposed by maxillary natural dentition showed a great problem. However, mandibular implant overdenture treatment has gained considerable recognition. Ten male patients with complete mandibular edentulous arch and opposing arch have full natural dentition. Patients were divided into two groups. All patients received two endosseous titanium implants. In Group I, patients were rehabilitated with conventional implant retained overdentures. While in Group II, Patients were rehabilitated with occlusal reactive implant overdentures. A Novel proposed bio-sensor was used to measure the amount of biting force on the implant retained overdenture. Quantitative electromyographic (EMG) signals of the masseter and anterior fibers of temporalis muscles were recorded, filtered and directly interfaced with a computer to represent the data graphically. The mean amplitude $(\mu \mathrm{V})$, turn, and activity were recorded at the baseline and after three months. The results revealed an increase in the muscle activity in group II after three months as compared to group I. Significant difference in bilateral biting force at the premolar-molar area was found between group $I$ and group II after three months. This study concluded that a resilient implant overdenture denture could be a desirable treatment in mandibular overdenture supported by two implants with resilient attachment and opposing natural dentition due to its easy fabrication and durability in use and increased muscle activity.
\end{abstract}

Keywords: Bio-Sensor; Biting Force; Mandibular Implant; Resilient Overdenture

\section{INTRODUCTION}

The main principle of any prosthetic treatment was based on the reduction of the transmitted load to the supporting structures. This can be achieved by improvement of denture retention, support, stability and reduction of the occlusal table, the broad coverage and the use of resilient materials. Mandibular single denture opposed by maxillary natural dentition showed a great problem due to smaller basal seat area of the mandibular arch compared to the maxillary arch and also greater forces transmitted to the supporting structures that are unable to resist them adequately. It is not known how much force is exerted when natural teeth in one arch are opposed by complete denture [1]. The resultant was a chronic soreness of the soft tissue, resorption of the alveolar ridge and inability to wear the denture. In recent decade, implant supported restoration has proven to be a reliable, predictable and effective treatment modality. Nowadays it appears that mandibular implant supporting overdentures are particularly successful and the use of implants has a great impact on the prosthodontic treatment of the edentulous patient. The treatment planning of edentulous jaw depends on the prosthetic design for distribution of implants over the arch, their location and their number. Moreover, it depends on the natural dentition or type of prosthesis in the opposing jaw and the occlusal scheme [2-5].

Over time, mandibular implant overdenture treatment has gained considerable recognition. It is an attractive treatment alternative because of its relative simplicity, invasiveness, and affordability. The prosthesis is supported by implant and mucosa and generally requires a smaller number of implants when compared with the totally implant supported prosthesis design. Fewer implants and a removable prosthesis offer a less complex and less expensive alternative for an edentulous Mandible [6].

Mandibular overdentures supported by only a few infraforaminal implants are regarded today as a geriatric treatment modality. The placement of only two implants 
will minimize the risk to patients and tissues. It considered as a true alternative to fixed prostheses in terms of economics and time-saving procedures. The combined mucosa implant supported overdenture is attached to two implants by means of resilient stud attachment or magnets [7].

There are many different attachments provided by a large number of manufacturers around the world. Most of these are compatible with the majority of the implant systems currently available and are divided into two major categories: bar and stud attachments. The choice of attachment is based basically on opinions and clinical experience rather than on real evidence and scientific findings [8]. Factors of selection attachment systems depend on the amount of space available, maintenance requirements, load distribution to the mucosa and to the implants, and the degree of retention $[9,10]$.

Implant overdenture construction necessitates the existence of sufficient room for the accommodation of the attachments. Lack of space can result in esthetic problems, fracture of the acrylic resin, or other technical problems [11]. Besides the necessary vertical space for the housing of the attachment, sufficient horizontal space is also critical for the structural integrity of the prosthesis. The O-ring is perhaps the most popular stud attachment which is available to the dental profession to increase the retention of implant supported overdentures. O-rings are elastomeric retentive attachments which are usually made of silicon and shaped like the inner tube of a tire. They are held within metallic retaining rings with undercut groove. The retaining rings are embedded within the denture base resin during the laboratory procedure or chair side with auto-polymerizing resin [12].

Occlusion also can be critical for implant longevity because of the nature of the potential load created by tooth contacts and the impact on the attachment of the bone to the titanium implant. In the natural dentition, the periodontal ligament has the capacity to absorb stress or allow for tooth movement, but the bone-implant interface seemingly has no capacity to allow movement of the implant. Vertical loads from mastication induce axial forces and bending movement that result in stress gradients in the implant as well as in the bone. A key factor for the success or failure of a dental implant is the manner in which stress is transferred to the surrounding bone [13].

The need for reduction of traumatic forces transmitted through the prosthesis has long been recognized and studies have shown that either a soft acrylic resin/silicone rubber can serve as a stress distributor and absorb some of the forces applied to the teeth. These dentures permit reaction to impact forces which allows independent movement of one or more teeth in function unlike the conventional dentures [14].
Bite force $(\mathrm{BF})$ results from the combined action of the jaw elevator muscles modified by jaw biomechanics and reflex mechanisms. The determination of individual bite force levels was done to understand jaw muscles strength, muscle function and activity and for evaluation of therapeutic effect of oral prostheses [15].

The most common technique for measuring BF was strain gages. They offer many advantages over other techniques such as simple installation that can be carried out with little training, available circuitry to measure its linear output over a large range of forces because of its easy estimation of the magnitude of the gage output with little well defined calculations. However, the resistance strain gages have their limitations. One of the most important limitations is the large size of the gauge applied to BF transducers. The large size of the gauges requires the height of the BF transducer to about 10 millimeters which causes a bite opening. This mouth opening will initiate a movement of the condyle along the articular eminence and therefore change the relationship to the closing muscles [16,17]. The non-linearity of human Biting Force (BF) provides a non-accurate computational analysis results. Recently the force sensing resistor, surface material of the sensor, and the computational software are important for determination of dental functional loading levels and increasing the medical analysis accuracy $[18,19]$. Therefore, this research was conducted to record the biting force and electromyographic activity resulting from occlusal reactive mandibular implant overdenture opposed by natural dentition.

\section{MATERIALS AND METHODS}

The study was reviewed and approved by Research Ethics Committee at the Faculty of Dentistry, King Abdulaziz University. The study design was explained to the patients and a signed consent was obtained from each patient. Ten male dental patients with complete mandibular edentulous arch, were selected from the Prosthodontic Department, King abdulaziz University, Dental Hospital. The opposing maxillary arch was full natural dentition. Their age ranged from 45 to 60 years. They were willing to accept mandibular implant over-denture treatment modality. They were healthy, free from any systemic disease with an acceptable level of oral hygiene. They were not subjected to chemotherapy or radiotherapy. Routine laboratory and medical investigations were performed for the patients undergoing implant surgery. Panoramic X-ray was made for every patient.

After collecting all the required diagnostic records for each patient. The patients were divided into two groups, group I and group II, each of five. Group I, the patients were rehabilitated with conventional implant retained mandibular overdentures. While in Group II, the Patients were rehabilitated with occlusal reactive mandibular 
implant overdentures.

In group I: conventional standard technique for mandibular single complete denture construction was used. Minor occlusal adjustment for natural teeth was carried out within the enamel. Posterior teeth were rearranged to satisfy the requirements of balanced occlusion. Adjustments in the artificial teeth were incorporated in preference to natural teeth. The finished dentures were delivered to the patient after performing the needed occlusal adjustment.

In group II: the occlusal reactive mandibular denture (Figure 1) was constructed as follow: the denture base was processed and used for jaw relation records. After the try-in stage, the regular procedure of flasking and wax elimination were carried out. A standard spacer of two strips of 0.001 tin foil was adapted under the artificial teeth in the flask and the split packing technique was followed by using a cellophane separator. The flask was opened, diatoric holes were made in the denture tooth with undercut to allow chemical bonding with soft resin. The spacer removed and sufficient amount of super soft resin (SS, GC America Inc., USA) was then applied and the dentures were processed [20].

Radiographic surgical stent was fabricated from clear heat acrylic replica of the constructed mandibular complete denture of both groups.

All the patients (group I and group II) received two endosseous titanium implants in the mandibular symphysis area (Imtec endure Co., USA). Mandibular overdenture with O-ring attachment over the implant was incorporated in the base of patient's denture. After two weeks the superstructures were attached to implant (they consist of O-rings, keeper and ball insert attachment (Figure 2) then connecting o-ring attachment to the

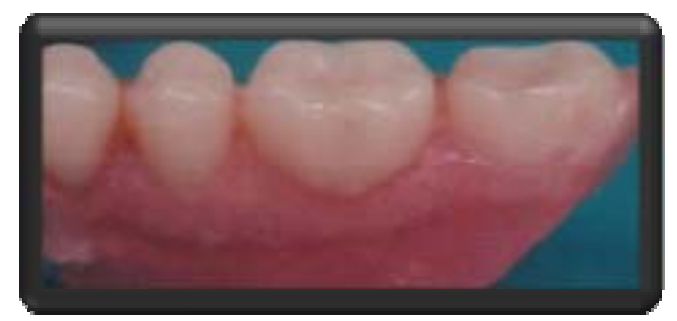

(a)

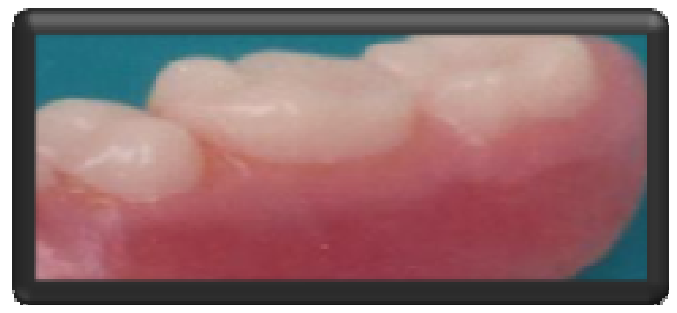

(b)

Figure 1. Occlusal reactive denture (a) bucal view, (b) lingual view. existing mandibular complete denture by direct clinical procedure as follow: The fitting surface of mandibular complete denture (in group I and group II) was relieved to create space for the metal housing (an elastic shim spacer) was placed around the O-ring assembly on the implant in the mouth to protect the gingiva from acrylic resin seeping into the mucosa and prevent acrylic resin from adhering to the implant) (Figure 3). Such spaces were filled with autopolymerized acrylic resin (Acrostone Cold Cure Acrylic Resin, Acrostone Co., England) at dough stage, the dentures were seated in the patient mouth (at centric relation) and to pick up the metal housing in the fitting surface of mandibular denture (Figure 4). The denture was removed, cleaned and examined for the orientation of the attachment inside the denture base. The elastic shim was removed. Smoothing and polishing the surface of the denture base were carried out and then occlusal equilibration was completed. Patient was motivated for oral hygiene procedure and then scheduled for radiographic examination.

\section{Novel Proposed Bio-Sensor for Recording the Biting Force}

A Novel proposed bio-sensor [18] was used to measure the amount of biting force on the implant retained overdenture. The sensor had been designed and encapsulated into a conventional safe bite guard. It had three major components: an inner sensor, an intermediate activator and an outer surface. The inner sensor was made of a circular conductive polymer pressure-sensing resistor. It

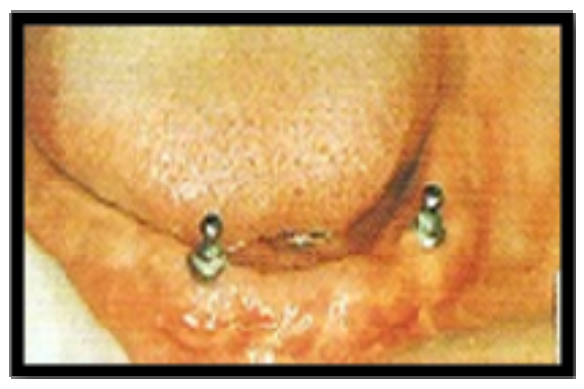

Figure 2. Superstructures were attached.

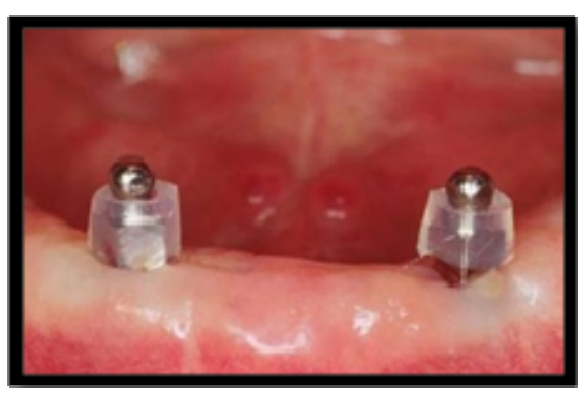

Figure 3. Elastic shim spacer was around the O-ring assembly on the implant. 
had two sheets were separated by a spacer that increased the peripheral thickness of the sensor to $0.5 \mathrm{~mm}$. Its basic characteristics were piezoresistive (piezo is derived from the Greek word piezein, "to squeeze") i.e. its resistance decreases with increasing normal pressure, the thermoplastic sheets also insulated the sensor. The proposed BF biosensor module produces frequency modulation using the FMC (force measuring circuit). These frequencies are transmitted to a microcontroller programmed in the manner that every received frequency is encoded into a recorded BF in Newton displayed on a LCD screen (Figures 5 and 6).

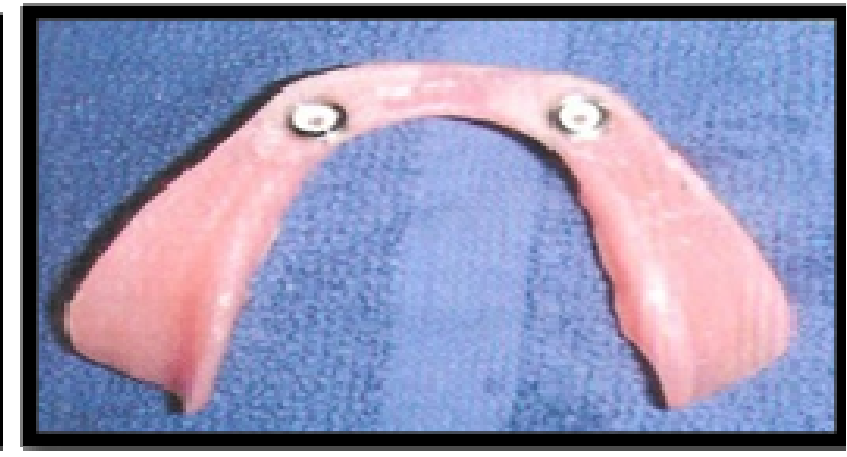

(b)

Figure 4. Pick up the metal housing in the fitting surface of mandibular denture.

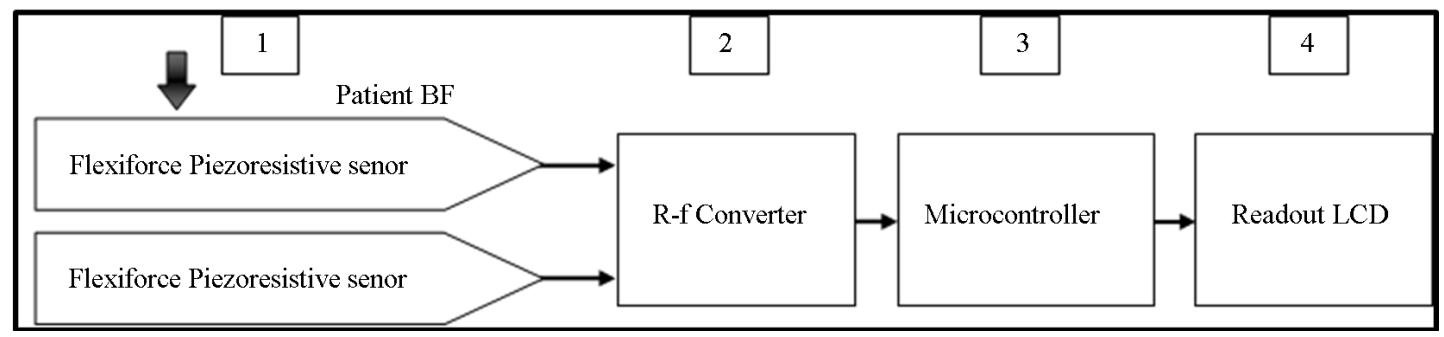

Figure 5. Proposed system diagram consisted of 1) piezoresistive sensor, 2) resitance to frequency cpnverter, 3) microcontroller based electronic circuit, 4) BF displayed on LCD screen.

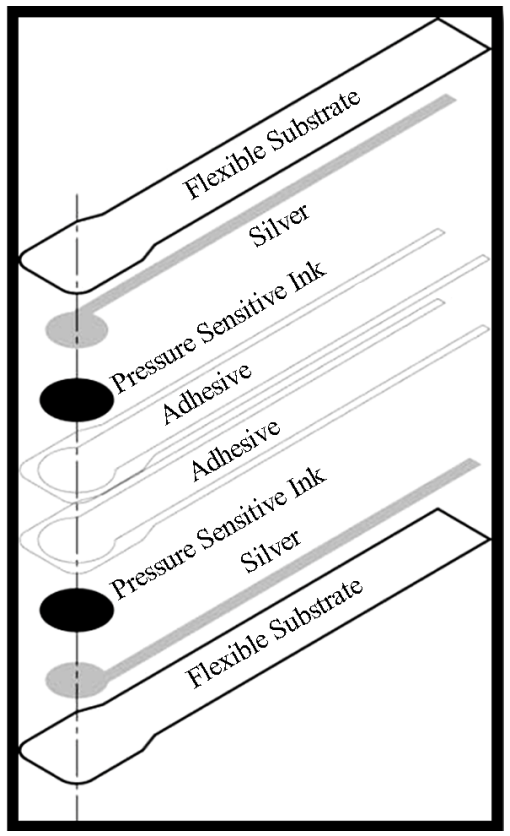

(a)

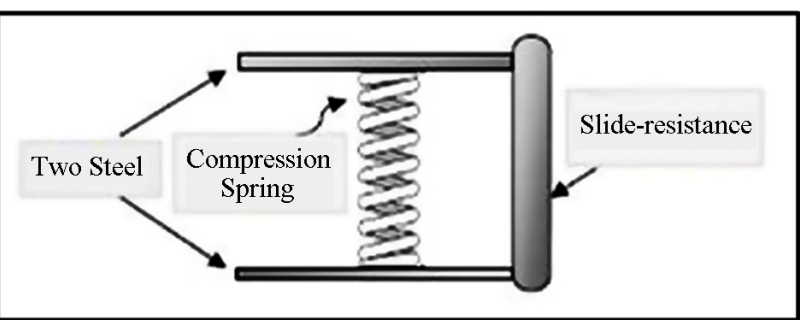

(b)

Figure 6. Flexiforce Sensor Components and 1) slide resistance, 2) two steel support and 3) steel spring. 


\section{CALIBRATION OF THE SENSOR}

Prior to intraoral measurement, the sensor bite force were calibrated and measured at different values of perpendicular forces against a universal testing machine (Instron Type 3382, German). The sensor was connected to micro-controlled electronic measuring circuit. The output signal from the load cell was conditioned, amplified and then recorded in a software program (Bluehill2). The correlation between the force recorded by Bluehill program according to the load cell and readout frequencies were recorded and plotted to calculate the linear equation between them (Figure 5).

\subsection{Procedure of Recording BF}

Patients were seated upright in the dental chair. They instructed to bite on the bite sensor device with closed and relaxed lips. Series of measurement at the right and left premolar-molar sides of the jaw were recorded with one minute rest between trials. The module output $\mathrm{BF}$ is measured and average value was calculated and recorded. The readings were recorded immediately at the day of insertion and after three months for group I and group II.

\subsection{Recording the Electromyographic Activity}

A quantitative EMG of the masseter and anterior fibers of temporalis muscles (representing the electrical activity) was recorded by means a standard electromyographic apparatus (Dentac Key Point Apparatus, Dentac Mod. 33 - 49, Denmark) at the baseline and after three months follow up periods. The patient was seated upright in a relaxed position without head support. The patients were instructed for wearing their dentures at least two hours before making the records. The two muscles studied (masseter and anterior fibers of temporalis) were first located. Skin was carefully cleaned prior to electrode placement, [21] with 70\% isopropyl alcohol allowing the conductive paste to moisten the skin surface adequately. An electroconductive paste (Ten20, D.O.Weaver and Co, 565-B Nucla way. Aurora, Co 80011, USA) was used as a conductive and fixing medium between skin and surface electrode. Patients were asked to close with maximum force for 10 seconds during which the EMG apparatus recorded free run EMG signals. This process of maximum biting and recording EMG signals was repeated 20 times in all. A rest period of $15-30 \mathrm{sec}$ was allowed between individual recording to avoid muscle fatigue.

The amplifier set up was set at sweep speed 100 $\mathrm{ms} /$ division, sensitivity $200 \mu \mathrm{v}$, division filter setting 20 $\mathrm{Hz}-10 \mathrm{KHz}$. Analysis of interference pattern (IPA) included three parameters 1) Number of turns (NT) or number of potential reversal of more than $100 \mu \mathrm{V}$ per time unit independent of baseline, 2) Mean amplitude
(MA) of the average is the amplitude between two turns measured by $\mu \mathrm{V}$ and 3) Activity that measured the fullness of IPA was defined as the time with electromyographic activity measured in milliseconds [22,23].

Electromyographic signals were recorded, amplified, filtered and directly interfaced with a computer to represent the data graphically. The data for the EMG activity was recorded for the right and left sides of both groups.

\subsection{Statistical Analysis}

All statistical analyses were performed using Statistical Package for the Social Science software (SPSS, version 17, Chicago, IL, USA). Descriptive statistics as means and standard deviations were used. T-test (unpaired) value of significance at 5 percent was performed for comparison between means at the baseline of implant over-denture insertion and after three-month follow up periods for each group. Paired t-test value was used for comparing between baseline and after 3 months in each group.

\section{RESULTS}

A calibration curve was showed in Figure 7, the plotted calibration was linear and the measurements were repeatable.

The mean value of amplitude $(\mu \mathrm{V})$, mean turn and mean activity of masseter muscle was showed in Table 1.

The mean value of amplitude $(\mu \mathrm{V})$, mean turn and mean activity of masseter muscle at the base line in group I and group II was not statistically significant.

Comparison between group I and group II for the mean value of amplitude $(\mu \mathrm{V})$, mean turn and mean activity of masseter muscle after three months follow up periods showed a significant difference at $5 \%$ level $\left(\mathrm{P}_{1}=\right.$ $0.001)$.

Comparison between group I and group II for the amplitude $(\mu \mathrm{V})$, mean turn and mean activity at baseline and after three months of follow up periods showed a significant increase at $5 \%$ level $\left(\mathrm{P}_{2}=0.001\right)$.

The mean value of the amplitude $(\mu \mathrm{V})$, mean turn and mean activity of temporalis muscle of group I and group II was showed in Table 2. Comparison between the mean amplitude $(\mu \mathrm{V})$ of group I and group II at the base line showed statistical significant difference $\left(\mathrm{P}_{1}=0.001\right)$, and after three months showed also statistical significant $\left(\mathrm{P}_{2}=0.001\right)$ at $5 \%$ level. Comparison between the baseline of group I and group II as regards the mean amplitude $(\mu \mathrm{V})$ with three months follow up periods showed a statistical significant difference at $5 \%$ level $\left(\mathrm{p}_{2}<0.001\right)$.

Comparison of the mean turn and mean activity of group II at the baseline was not statistical significant. Also after three months follow up periods showed no 


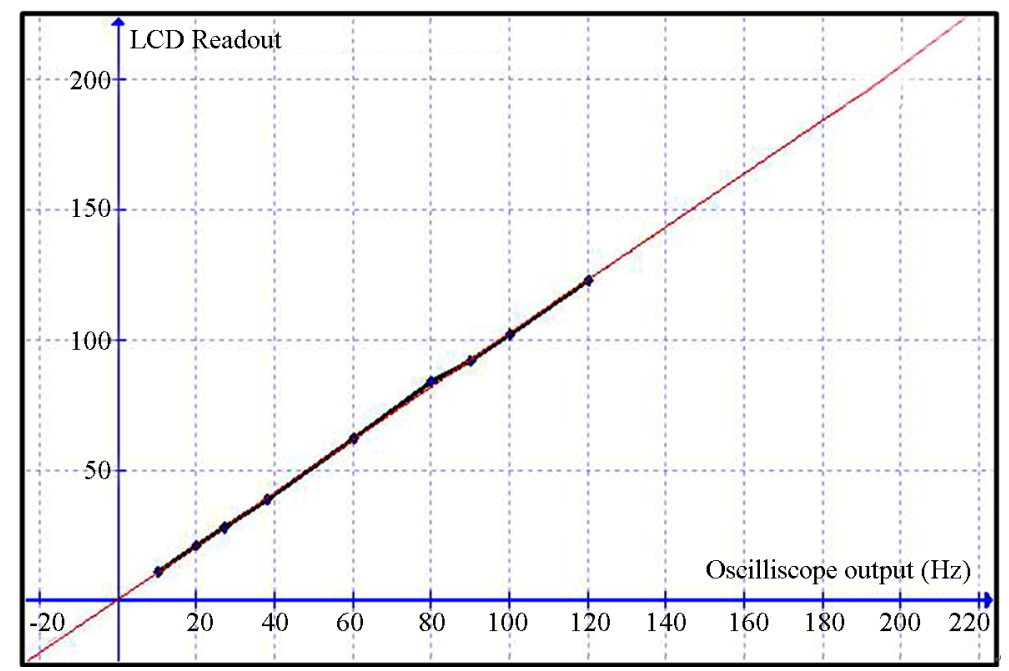

Figure 7. Plotted calibration curve between the output frequency circuit and the resultant of programmed microcontroller was linear.

Table 1. Comparison of electromyographic parameters of masseter muscles bilaterallyat different follow up periods in the two study grops.

\begin{tabular}{|c|c|c|c|c|}
\hline & & Group I & Group II & $\mathbf{p}_{1}$ \\
\hline & Baseline Mean \pm SD & $395.60 \pm 4.62$ & $401.60 \pm 5.03$ & 0.085 \\
\hline \multirow[t]{3}{*}{ Amplitude $(\mu \mathrm{V})$} & After 3 months Mean \pm SD & $605.40 \pm 4.56$ & $619.80 \pm 1.48$ & $<0.001^{*}$ \\
\hline & $\mathbf{p}_{2}$ & $<0.001^{*}$ & $<0.001^{*}$ & \\
\hline & Baseline Mean \pm SD & $210.20 \pm 3.19$ & $214.20 \pm 4.21$ & 0.129 \\
\hline \multirow[t]{3}{*}{ Turn } & After 3 months Mean \pm SD & $325.0 \pm 4.12$ & $238.0 \pm 7.58$ & $<0.001^{*}$ \\
\hline & $\mathbf{p}_{2}$ & $<0.001^{*}$ & $<0.001^{*}$ & \\
\hline & Baseline Mean \pm SD & $12.80 \pm 1.30$ & $12.56 \pm 0.52$ & 0.712 \\
\hline \multirow[t]{2}{*}{ Activity \% } & After 3 months Mean \pm SD & $16.0 \pm 1.22$ & $21.0 \pm 1.41$ & $<0.001^{*}$ \\
\hline & $\mathbf{p}_{2}$ & $<0.001^{*}$ & $<0.001^{*}$ & \\
\hline
\end{tabular}

$\mathrm{p}_{1}$ : $\mathrm{p}$ value for Student $\mathrm{t}$-test for comparing between the two studied group; $\mathrm{p}_{2}$ : $\mathrm{p}$ value for Paired t-test for comparing between baseline and after 3 months in each group; ${ }^{*}$ : Statistically significant at $\mathrm{p} \leq 0.05$.

Table 2. Comparison of electromyographic parameters of temporalis muscles bilaterally at different follow up periods in the two study groups.

\begin{tabular}{|c|c|c|c|c|}
\hline & & Group I & Group II & $\mathbf{p}_{1}$ \\
\hline & Baseline Mean \pm SD & $367.0 \pm 3.91$ & $393.40 \pm 3.44$ & $<0.001^{*}$ \\
\hline \multirow[t]{3}{*}{ Amplitude $(\mu \mathrm{V})$} & After 3 months Mean \pm SD & $415.40 \pm 3.91$ & $553.40 \pm 3.97$ & $<0.001^{*}$ \\
\hline & $\mathbf{p}_{2}$ & $<0.001^{*}$ & $<0.001^{*}$ & \\
\hline & Baseline Mean \pm SD & $247.80 \pm 59.61$ & $200.60 \pm 7.02$ & 0.152 \\
\hline \multirow[t]{3}{*}{ Turn } & After 3 months Mean $\pm \mathrm{SD}$ & $313.0 \pm 4.95$ & $308.20 \pm 5.76$ & 0.195 \\
\hline & $\mathbf{p}_{2}$ & 0.084 & $<0.001^{*}$ & \\
\hline & Baseline Mean \pm SD & $10.90 \pm 1.39$ & $12.0 \pm 3.08$ & 0.488 \\
\hline \multirow[t]{2}{*}{ Activity \% } & After 3 months Mean $\pm \mathrm{SD}$ & $18.0 \pm 3.39$ & $19.0 \pm 2.92$ & 0.631 \\
\hline & $\mathbf{p}_{2}$ & $0.002^{*}$ & 0.091 & \\
\hline
\end{tabular}

$\mathrm{p}_{1}$ : $\mathrm{p}$ value for Student t-test for comparing between the two studied group; $\mathrm{p}_{2}$ : $\mathrm{p}$ value for Paired t-test for comparing between baseline and after 3 months in each group; ${ }^{*}$ : Statistically significant at $\mathrm{p} \leq 0.05$. 
statistical significant.

Comparing the mean turn of group II at the baseline with the three months was statistically significant $\left(\mathrm{P}_{2}<\right.$ 0.001 ).

A statistical significant difference was observed in the mean activity of group I between the base line and after three months $\left(\mathrm{P}_{2}=0.002\right)$.

Comparison between the mean value of bilateral biting force of premolar-molar area at the baseline and after three months of follow up periods for both group I and group II showed a statistically significant at $5 \%$ level $\left(\mathrm{P}_{1}\right.$ $=0.0140 .003$ ), respectively as shown in Table 3 .

Comparison between groupI and group II of bilateral biting force of premolar-molar area at the baseline with three months follow up period showed statistical significant increase at $5 \%$ level $\left(\mathrm{P}_{2}=0.001\right.$ and 0.001$)$.

The mean value of anterior biting force in group I and group II was showed in Table 3, there was no statistical significant difference between group I and group II at the baseline, while after three months follow up period there was a statistical significant difference at $5 \%$ level $\left(\mathrm{P}_{1}=\right.$ 0.007).

A statistical significant increase in anterior biting force was observed in group I and group II after three months follow up periods $\left(\mathrm{P}_{2}=0.003\right.$ and 0.007$)$ respectively at $5 \%$ level.

\section{DISCUSSION}

Mandibular two implant overdenture have been recognized as the first choice of treatment for edentulous patients when compared with conventional complete denture. The main factors associated with the superior effectiveness are due to retention and stability provided by the attachment mechanism connecting the implant to the denture base. Different attachments together with two implants retained overdenturess, represent a predictable and successful option to treat edentulous patients [24].

Selected patients had full complement of natural teeth opposing to edentulous mandibular arch as it would affect the functional state of the masticatory system and so the maximum voluntary occlusal force. Occlusal form of the remaining natural teeth, can dictate the occlusal form of the denture. The natural teeth may be over-erupted or tilted and their cusps high and sharp. As a result, occlusion and articulation will involve contacting of the inclined planes of the cusps in such a way that the denture will continually be thrust or dragged horizontally on the ridge. Additionally minor occlusal interferences included in this study were adjusted for establishing free occlusion. Literature recommended in these cases a minimum of four implants with a fixed implant prosthesis as the condition of the opposing jaw influences the occlusal concepts. However, the recent literature review exhibits a high success rate for using fewer implants (two) for mandibular overdenture with resilient attachment system in older patients in terms of economics and time saving procedures and at the same time minimizes the risk to patient and tissues [3].

The occlusal reactive mandibular implant overdenture was used in our study. It was made of resilient zone interposed between a rigid denture base and the artificial teeth which may be contributed to reduce the occlusal load transmitted to the implant and minimize the effect of deflective occlusal contacts [20].

$\mathrm{BF}$ determined in this study by novel proposed bio-sensor because it is safe, easy to fabricate, chemically and physically stable with high sensitivity. The novel sensor based on conductive polymer film useful for determination of occlusal loading level and functioning as force absorber and not damaged or ruptured by tooth cusps. The material used was soft and allowed the test patient to obtain a firm grip in all position. The conductive material are sensitive to mechanical stress that can be molded into various shapes and sizes with spring fixed to variable resistance compressed and can be measured using the connected circuit. This sensor exhib-

Table 3. Comparison of the mean value of the bilateral bilateral biting force at premolar molar region and anterior region in the two study groups.

\begin{tabular}{ccccc}
\hline & & Group I & Group II & p $_{\mathbf{1}}$ \\
\hline \multirow{2}{*}{ At premolar-molar region } & Baseline Mean \pm SD & $185.40 \pm 10.36$ & $201.80 \pm 5.36$ & $0.014^{*}$ \\
& After 3 months Mean \pm SD & $232.20 \pm 4.97$ & $244.0 \pm 4.0$ & $0.003^{*}$ \\
At the anterior region & $\mathbf{p}_{2}$ & $0.001^{*}$ & $<0.001^{*}$ & 0.715 \\
& Baseline Mean \pm SD & $144.80 \pm 4.32$ & $145.80 \pm 4.02$ & $0.007^{*}$ \\
\hline
\end{tabular}

$\mathrm{p}_{1}$ : $\mathrm{p}$ value for Student t-test for comparing between the two studied group; $\mathrm{p}_{2}$ : $\mathrm{p}$ value for Paired t-test for comparing between baseline and after 3 months in each group; ${ }^{*}$ : Statistically significant at $\mathrm{p} \leq 0.05$. 
ited a linear relationship between the frequency of the circuit and the resultant of programmed microcontroller.

The significant increase of the BF in molar-premolar area than the anterior area could be attributed to the lever effect of the mandible and the function of implants in the edentulous jaw was taken over by the receptors in the mucosa and the periosteal mechanoreceptors as well as intraosseous nerve ending and functional adaptation of the occlusally reactive mandibular overdenture. The dental implant prevents tilting of the denture during biting and thus decrease pain factor that limits maximium BF due to reflex mechanism. The degree of tissue support of mandibular denture by dental implants also improves oral function [25-27].

Quantitative electromyographic interference pattern analysis is a non invasive, objective, and quantitative tool for identification of the degree of muscle activity, monitoring muscle fatigue, as well as chronic muscle pain. Number of turns, mean amplitude and activity are valuable parameters of IPA for assessing muscle activity as well as the effect of therapeutic intervention. The masseter and temporalis muscles are those most often assessed in clinical evaluations because they are the most superficial, and they are the only accessible to surface EMG examination. EMG activity was recorded during maximum voluntary clench to assess masseter and temporalis muscles before treatment and in follow up assessments [28-30].

Statistical analysis of the results showed that the electromyographic activity of the masseter muscle was significantly higher than the temporalis muscle. This may be attributed to the greater influence and the greater efforts exerted by the masseter muscle on the denture than the temporalis muscle. This result was in accordance with the results of Landulpho [31].

In this study, the occlusal reactive implant overdenture act as shock absorber of some of kinetic energy applied by artificial teeth so that the hard basal seat of the denture receives less impact force led to reactivation of the motor units (MUs) and an increase in force of contraction that was reflected by an increase in interference pattern parameters values as well as the occlusal force measurement at different periods of follow up assessments. These results can be explained as the force produced by a muscle under voluntary contraction is based on the firing frequency and the recruitment of MUs. Increasing either the firing frequency or the number of recruited MUs contributes to increasing the muscle force on maximum voluntary contraction. There is a linear relationship between the force of contraction and the mean amplitude as well as number of turns of interference pattern. At higher levels of contraction, the firing rate of MUs has large motor unit action potential amplitude [32,33].

\section{CONCLUSION}

Types of overdenture and occlusal concepts are primary goals at the beginning of treatment. The proposed biosensor is safe for introrally application (in-vivo) without alteration of patient bites and for evaluation of the biomechanics of the prosthetic appliances. The resilient layer denture could be a desirable treatment in mandibular overdenture supported by two implants with resilient attachment and opposing natural dentition due to its easy fabrication and durability in use and increased muscle activity.

\section{ACKNOWLEDGEMENTS}

We are grateful to Professor Mazhar Tayel (Department of Electrical Engineering, Alexandria University), and Professor Seham Tayel (King Abdulaziz University) for their valuable advice and comments in this research.

\section{REFERENCES}

[1] Rahn, A.O. and Heartwell, C.M. (2000) Text book of complete denture. 5th Edition, PMPH-USA, Philadelphia.

[2] Sharry, J.J. (1974) Complete Denture Prosthodontics. 3rd Edition, McGraw-Hill, New York, 310-311

[3] Anderson, J.N. and Storer, R. (1966) Immediate and Replacements Dentures. Blackwell Scientific Publications, Oxford, 4.

[4] Ellinger C.W., Rayson, J.H. and Henderson, D. (1971) Single complete denture. Journal of Prosthetic Dentistry, 26, 4-10.

http://dx.doi.org/10.1016/0022-3913(71)90023-0

[5] Singh, L.K. and Singh, R. (2013) Single complete denture in mandibular arch opposing natural dentition. A case report. Nitte University Journal of Health Science, 3, 72-75.

[6] Johns, R.B., Jemt, T., Heath, M.R., et al. (1992) A multicenter study of overdentures supported by Brånemark implants. The International Journal of Oral \& Maxillofacial Implants, 7, 513-522

[7] Mericske-Stern, R.D., Taylor, T.D. and Belser, U. (2000) Management of the edentulous patient. Clinical Oral Implants Research, 11, 108-125. http://dx.doi.org/10.1034/j.1600-0501.2000.011S1108.x

[8] Trakas, T., Michalakis, K., Kang, K. and Hirayama, H. (2006) Attachment Systems for Implant Retained Overdentures: A literature Review. Implant Dentistry, 15, 2434. http://dx.doi.org/10.1097/01.id.0000202419.21665.36

[9] Burns, D.R., Unger, J.W., Elswick, R.K. and Giglio, J.A. (1995) Prospective clinical evaluation of mandibular implant overdentures. Part II: Patient satisfaction and preference. Journal of Prosthetic Dentistry, 73, 364-369. http://dx.doi.org/10.1016/S0022-3913(05)80332-4

[10] Burns, D.R., Unger, J.W., Elswick, R.K. and Beck, D.A. (1995) Prospective clinical evaluation of mandibular implant overdentures. Part I: Retention, stability and tissue 
response. Journal of Prosthetic Dentistry, 73, 354-363. http://dx.doi.org/10.1016/S0022-3913(05)80331-2

[11] Zarb, G.A. and Schmitt, A. (1996) The edentulous predicament. I: A prospective study of the effectiveness of implant supportedfixed prostheses. The Journal of the American Dental Association, 127, 59-65.

[12] Winkler, S., Piermatti, J., Rothman, A. and Siamos, G. (2002) An overview of the O-ring implant overdenture attachment: Clinical reports. Journal of Oral Implantology Online, 28, 82-86.

http://dx.doi.org/10.1563/1548-1336(2002)028<0082:AO OTOI $>2.3 . \mathrm{CO} ; 2$

[13] Sohn, B.S., Heo, S.J., Koak, J.Y., Kim, S.K. and Lee, S.Y., (2011) Strain of implants depending on occlusion types in mandibular implant-supported fixed prostheses. Journal of Advanced Prosthodontics, 3, 1-9.

[14] Geng, J.P., Tan, K.B. and Liu, G.R. (2001) Application of finite element analysis in implant dentistry: A review of the literature. Journal of Prosthetic Dentistry, 85, 585598. http://dx.doi.org/10.1067/mpr.2001.115251

[15] Fernandes, C.P., Glantz, P.F., Svensson, S.T. and Bergmark, A. (2003) A novel sensor bite force determination. Dental Materials, 19, 118-126. http://dx.doi.org/10.1016/S0109-5641(02)00020-9

[16] Ortu G. (2002) A new device for measuring mastication force. Annals of Anatomy, 184, 393-396. http://dx.doi.org/10.1016/S0940-9602(02)80063-2

[17] Gibbs, C.H., Mahan, P.E., Mauderli, A., Lundeen, H.C. and Walsh, E.K. (1986) Limits of human bite strength. Journal of Prosthetic Dentistry, 56, 226-229. http://dx.doi.org/10.1016/0022-3913(86)90480-4

[18] Tayel, M., Elaskary, S. and Tamer, N. (2012) A bio-sensory system for increase implant longevity for occlusal analysis. 2nd International Conference on Advances in Computational Tools for Engineering Applications (AC TEA), Beirut, 12-15 December 2012, 7-10. http://dx.doi.org/10.1109/ICTEA.2012.6462908

[19] Fernandes, C.P., Glantz, P.F., Svensson, S.T. and Bergmark, A. (2003) A novel sensor bite force determination. Dental Materials, 19, 118-126. http://dx.doi.org/10.1016/S0109-5641(02)00020-9

[20] Bernhausen, E.R. (1979) Resilient material used between the teeth and the denture base: A preliminary report. Journal of Prosthetic Dentistry, 25, 258-264. http://dx.doi.org/10.1016/0022-3913(71)90186-7

[21] Clancy, E.A., Morin, E.L. and Merletti, R. (2002) Sampling, noise-reduction and amplitude estimation issues in surface electromyography. Journal of Electromyography \& Kinesiology, 12, 1-16. http://dx.doi.org/10.1016/S1050-6411(01)00033-5

[22] Soderberg, G.L. and Knutson, L.M. (2000) Aguide for use and interpretation of kinesiologic electromyographic data. Physical Therapy, 80, 485-498.

[23] Armijo, S. and Magee, D.J. (2007) Electromyograpic activity of the masticatory and cervical muscles during resisted jaw opening movement. Journal of Oral Rehabilitation, 34, 184-94. http://dx.doi.org/10.1111/j.1365-2842.2006.01664.x

[24] Klemetti, E. (2008) Is there a certain number of implants needed to retain an overdenture? Journal of Oral Rehabilitation, 35, 80-84. http://dx.doi.org/10.1111/j.1365-2842.2007.01825.x

[25] Bakke, M. (2006) Bite force and occlusion. Seminars in Orthodontics, 12, 120-126. http://dx.doi.org/10.1053/i.sodo.2006.01.005

[26] Fontijn-Tekamp, F.A., Slagter, A.P., Van't Hof, Van Der Bilt, A., Writter, D.J., Kalk, W. and Jansen, J.A. (2000) Bitting and chewing in overdentures, full dentures,and natural dentition. Journal of Dental Research, 79, 15191524. http://dx.doi.org/10.1177/00220345000790071501

[27] Miyaura, K., Morita, M., Matsuka, Y., Yamashita, A. and Watanabe, T. (2000) Rehabilitation of biting abilities in patients with different types of dental prostheses. Journal of Oral Rehabilitation, 27, 1073-1076. http://dx.doi.org/10.1046/j.1365-2842.2000.00620.x

[28] Cooper, B.C. (1997) The role of bioelectronic instrumenttation in the documentation and management of temporomandibular disorders. Oral Surgery, Oral Medicine, Oral Pathology, Oral Radiology, 83, 91-100. http://dx.doi.org/10.1016/S1079-2104(97)90098-6

[29] Lindquist, L., Carlsson, G.E. and Hedegard, B. (1986) Changes in 28 bite force and chewing efficiency after denture treatment in edentulous patients with denture adaptation difficulties. Journal of Oral Rehabilitation, 13, 21-29. http://dx.doi.org/10.1111/j.1365-2842.1986.tb01552.x

[30] Granick, J. (1975) Reproducility of the electromyogram. Journal of Dental Research, 54, 867-871. http://dx.doi.org/10.1177/00220345750540042701

[31] Landulpho, A.B., E Silva, W.A.B., E Silva, F.A. and Viti, M. (2004) Electromyographic evaluation of masseter and anterior temporalis muscles in patients with temporomandibular disorders following interocclusal appliance treatment. Journal of Oral Rehabilitation, 31, 95-98. http://dx.doi.org/10.1046/j.0305-182X.2003.01204.x

[32] Ferrario, V.F., Tartaglia, G.M., Luraghi, F.E. and Sforza, C. (2007) The use of surface electromyography as a tool in differentiating temporomandibular disorders from neck disorders. Manual Therapy, 12, 372-379. http://dx.doi.org/10.1016/j.math.2006.07.013

[33] Finsterer, J. (2001) EMG-interference pattern analysis. Journal of Electromyography \& Kinesiology, 11, 231-246. http://dx.doi.org/10.1016/S1050-6411(01)00006-2 